Biotechnic \& Histochemistry

\title{
Expression of ATP6V1C1 during oral carcinogenesis
}

\section{MG Oliveira Alves, CFL Carta, M-E Padín-Iruegas, M Pérez-Sayáns, JM Suarez- Peñaranda, JS Issa, A García-García \& JD Almeida}

To cite this article: MG Oliveira Alves, CFL Carta, M-E Padín-Iruegas, M Pérez-Sayáns, JM Suarez-Peñaranda, JS Issa, A García-García \& JD Almeida (2016) Expression of ATP6V1C1 during oral carcinogenesis, Biotechnic \& Histochemistry, 91:4, 263-268, DOI: 10.3109/10520295.2016.1144078

To link to this article: https://doi.org/10.3109/10520295.2016.1144078

\section{Published online: 16 Mar 2016.}

Submit your article to this journal $\widetilde{ }$

山 Article views: 64

View Crossmark data \lceil 


\title{
Expression of ATP6V1C1 during oral carcinogenesis
}

\author{
MG Oliveira Alves ${ }^{1,2}$, CFL Carta1 ${ }^{1}$ M-E Padín-Iruegas ${ }^{3}$, M Pérez-Sayáns $^{4}$, \\ JM Suarez-Peñaranda ${ }^{5}$, JS Issa ${ }^{6}$, A García-García ${ }^{4}$, JD Almeida ${ }^{1}$ \\ ${ }^{1}$ Department of Biosciences and Oral Diagnosis, Institute of Science and Technology, UNESP - Univ Estadual Paulista, \\ São José dos Campos, São Paulo, Brazil, ${ }^{2}$ University Braz Cubas, Mogi das Cruzes, São Paulo, Brazil, ${ }^{3}$ Human \\ Anatomy and Embryology Area, Department of Functional Biology and Health Sciences, University of Vigo, \\ Pontevedra, Spain, ${ }^{4}$ Oral Medicine, Oral Surgery and Implantology Unit, Faculty of Medicine and Dentistry, Santiago \\ de Compostela, Spain, ${ }^{5}$ Department of Pathology and Forensic Sciences, University Hospital and School of Medicine \\ of Santiago de Compostela, Santiago de Compostela, Spain, and ${ }^{6}$ Smoking Cessation Program, Area of Cardiology, \\ Heart Institute, University of São Paulo School of Medicine, Hospital das Clínicas, São Paulo, Brazil
}

Accepted January 16, 2016

\begin{abstract}
We investigated the gene and protein expressions of V-type ATPase protein subunit C1 (ATP6V1C1) in cases of oral squamous cell carcinoma (OSCC) and contralateral normal mucosa in smokers, nonsmokers and former smokers. Subjects were separated into five groups of 15: group 1, smokers with OSCC; group 2, normal contralateral mucosa of OSCC patients; group 3, chronic smokers; group 4, former smokers who had stopped smoking 1 year earlier; group 5, individuals who had never smoked. Exfoliative cytology specimens from oral mucosa of smokers, former smokers and nonsmokers showed normal gene and protein expression. We found significantly greater gene expression in the OSCC group than in the nonsmoker groups. No difference in gene expression was observed between normal contralateral mucosa and nonsmoker groups, smoker and nonsmoker groups or former smoker and nonsmoker groups. We observed intense immunostaining for ATP6V1C1 protein in all cases of OSCC and weak or no staining in smoker, former smoker and nonsmoker groups. Significantly greater expression of ATP6V1C1 protein was observed in the OSCC group compared to the other groups, which supports the role of ATP6V1C1 in effecting changes associated with oral cancer. Analysis of the mucosae of chronic smokers, former smokers and the normal contralateral mucosa of patients with OSCC showed unaltered ATP6V1C1 gene and protein expression. Early stages of carcinogenesis, represented by altered epithelium of chronic smokers, had neither gene nor protein alterations as seen in OSCC. Therefore, we infer that the changes in ATP6V1C1 occur during later stages of carcinogenesis. Our preliminary study provides a basis for future studies of using ATP6V1C1 levels for detecting early stage OSCC.
\end{abstract}

Key words: ATP6V1C1, gene expression, immunocytochemistry, oral cancer, polymerase chain reaction, smoking, squamous cell carcinoma

Oral squamous cell carcinoma (OSCC) is the most common malignancy of the oral cavity (Lambert et al. 2011). Cigarette smoking is a major risk factor for the development of OSCC (Winn 2010, Scully et al. 2000). Changes in the control mechanisms of

Correspondence: Mônica Ghislaine Oliveira Alves, 777 Engenheiro Francisco José Longo Avenue, São Dimas. São José dos Campos, SP, Brazil 12245-000. Phone: + 55 1232072962/+55981278200, fax: + 55 1239479010, e-mail: mgoliveiraalves@ gmail.com

Color versions of one or more of the figures in the article can be found online at www.tandfonline.com/ibih (C) 2016 The Biological Stain Commission

Biotechnic \& Histochemistry 2016, 91(4): 263-268. cell growth and increased proliferative activity are observed in smokers, even in the absence of clinical lesions (Fontes et al. 2008).

Exfoliative cytology is a useful tool for early detection and monitoring of cellular changes (Fontes et al. 2008); it is a simple and noninvasive technique for obtaining samples for gene expression studies (Reboiras-López et al. 2012). We investigated the gene expression levels of tumor markers in cytology samples to detect molecular changes before alterations occurred in cell morphology (Pérez-Sayáns et al. 2010a). Cells of the superficial epithelial layers contain information about the changes that 
occurred during the cell maturation process prior to desquamation (Fontes et al. 2008).

Carcinogenesis is accompanied by metabolic disorders, acidification of the extracellular environment and intracellular alkalization (MartinezZaguilan et al. 1993, Cardone et al. 2005). Increased intracellular $\mathrm{pH}$ accompanies increased DNA synthesis, which potentially produces neoplastic cells (Reshkin et al. 2000).

The vacuolar type $\mathrm{H}+$ ATPase (V-ATPases) is an ATP-driven enzyme that transforms the energy of ATP hydrolysis to active transport of $\mathrm{H}+$ (Beyenbach et al. 2006). Cellular acidosis and the regulation of $\mathrm{pH}$ is controlled mainly by V-ATPases (PérezSayáns et al. 2009a); the V-type ATPase protein subunit C1 (ATP6V1C1) participates in $\mathrm{pH}$ regulation (Otero-Rey et al. 2008). Therefore, ATP6V1C1 controls the protein complex assembly that regulates V-ATPases (Inoue et al. 2005). Otero-Rey et al. (2008) reported high expression of the ATP6V1C1 gene in OSCC biopsy samples, which suggests that this protein may be involved in malignant transformation. These investigators suggested that ATP6V1C1 participates in V-ATPase modification (Otero-Rey et al. 2008). Pérez-Sayáns et al. (2010a) reported overexpression of this gene in exfoliative cytology samples of OSCC.

When a tissue is exposed to a carcinogen, it may exhibit changes associated with the exposure to its full extent, a phenomenon known as field cancerization. In other words, all exposed tissue may undergo carcinogenesis (Kaufmann et al. 2010, Braakhuis et al. 2005). Smoking tobacco is the most common carcinogen for development of oral cancer (Baric et al. 1982).

Although investigations of the role of tobacco in oral carcinogenesis using oral cytological samples have been reported (Fontes et al. 2008, Pavanello et al. 2006), reports of molecular evaluation of patients are scarce. Therefore, we investigated the gene and protein expressions of ATP6V1C1 in oral carcinogenesis using samples of oral mucosa of patients with OSCC, their contralateral mucosa, and mucosae of smokers, nonsmokers and former smokers. We hypothesized that during early stages of carcinogenesis and during field cancerization, changes in ATP6V1C1 gene and protein expression may be observed.

\section{Material and methods}

\section{Patients and samples}

Our study was approved by the Research Ethics Committees of both Galicia, Spain and the Institute of Science and Technology, UNESP-Univ Estadual Paulista. Informed consent was obtained from each participant. All patients were given extra- and intraoral clinical examinations prior to sampling.

Our samples consisted of oral mucosa cytology smears obtained from men recruited from the Oral Medicine, Oral Surgery and Implantology Unit of the Faculty of Medicine and Dentistry, University of Santiago de Compostela; the Smoking Cessation Program of the Heart Institute, University of São Paulo School of Medicine; and the Oral Medicine outpatient clinic of the Institute of Science and Technology, UNESP. Subjects were divided into five groups of 15: OSSC group, smokers with OSCC; normal contralateral mucosa group, contralateral normal mucosa of OSCC patients; smoker group, chronic smokers who consumed 20 or more cigarettes/day; former smoker group, former smokers who had stopped smoking 1 year earlier; and nonsmoker group, individuals who never smoked (nonsmokers). All patients in the OSCC group were also chronic smokers, who consumed at least 20 cigarettes/day. The following data were collected for the OSCC group: age, gender and tumor site; the other groups were age ( \pm 3 years) and gender matched. The inclusion criteria for smoker, former smoker and nonsmoker groups were as described previously by Lima et al, (2010): male individuals with no history of oral malignancy, no visible abnormal clinical signs at the sample sites, and consumption of less than $20 \mathrm{~g}$ of alcohol/week. All patients in the OSCC group had drinking habits.

\section{Exfoliative cytology}

For exfoliative cytology, we collected cells by rotating a brush ten complete turns at each sampling location. For qPCR evaluation, cells were collected from all groups using an Orcellex Brush ${ }^{\circledR}$ (Rovers Medical Devices, Oss, The Netherlands). Samples were transported in DNase-, RNase- and pyrogenfree tubes containing $2 \mathrm{ml}$ RPMI (Microvet, Madrid, Spain) protected from light and stored in the dark at $2-10^{\circ} \mathrm{C}$ (Pérez-Sayáns et al. 2010a).

Smears were prepared on silanized glass slides for immunohistochemical evaluation. Exfoliated cells were collected from the tumor site in the OSCC group and from normal mucosa contralateral to the OSCC tumor in the normal contralateral mucosa group. In the smoker, former smoker and nonsmoker groups, cells were obtained from sites that corresponded to the OSCC sites. No mouthwash was used before samples were collected (Fontes et al. 2008). Smears from all groups except OSCC were prepared on silanized glass slides and stained 
with anti-ATP6V1C1 antibody (Santa Cruz Biotechnology, Heidelberg, Germany). OSCC smears were inadequate for evaluation; therefore, OSCC lesion fragments were embedded in paraffin and $3 \mu \mathrm{m}$ sections were placed on silanized glass slides for staining using the anti-ATP6V1C1 antibody.

\section{Real-time quantitative reverse transcriptase- polymerase chain reaction ( $q P C R$ )}

All samples were processed at the Laboratory of Molecular Biology, Hospital Clinico Universitario de Santiago de Compostela, Spain. Total RNA was extracted using a Trizol kit (Ambion Inc., Carlsbad, $\mathrm{CA})$ as recommended by the manufacturer, then resuspended in $20 \mu 1$ RNA storage buffer (Ambion Inc., Carlsbad, CA). One microliter of RNA was used to measure the absorbance at 260 (A260) and 280 (A280) nm using the NanoDrop 1000 spectrophotometer for each sample (Thermo Scientific, Wilmington, DE). The RNA concentration was estimated by multiplying by 40 the value of A260 (ng/ml). The purity, which indicates the quality of RNA, was assessed by the A260/A280 and A260/ A230 ratios, where A260/A280 ratios between 1.8 and 2.0 and A260/A230 ratios close to 1.7 suggest RNA free of contamination. An appropriate blank solution was used to zero the spectrophotometer. Integrity was checked by electrophoresis using 1\% agarose gel (Invitrogen, Carlsbad, CA), staining by ethidium bromide and visualization on a transilluminator. Only intact and good quality RNA was used; nonconforming samples were discarded.

One microgram of the extracted total RNA was treated with DNase I (Ambion Inc.) and transcribed into complementary DNA (cDNA) using the SuperScript $^{\circledR}$ III First-Strand Synthesis SuperMix for qPCR Kit (Invitrogen), according to the instructions provided by the manufacturer.

The primer sequences, which were specific for humans, were confirmed by the NCBI/Gene Bank website. There are primers information in Table 1. The reference gene qPCR primer sequences used were described by Rentoft et al. (2010): ACTB, OAZ1, GAPDH, RPL27, HPRT1, TUBA6. The primers were tested in all cases and the results were analyzed by RefFinder that integrates computer programs geNorm, Normfinder, BestKeeper and the comparative $\mathrm{Ct}$ method. GAPDH was selected as the reference gene.

The qPCR method was used to measure the amount of cDNA during the exponential phase of the amplification reaction. The SYBR ${ }^{\circledR}$ Green fluorophore (Platinum ${ }^{\circledR}$ SYBR ${ }^{\circledR}$ Green qPCR SuperMixUDG; Applied Biosystems, Framingham, MA) was used for detection. The cDNA $2 \mu \mathrm{l} / 20 \mu \mathrm{l}$ reaction was used for each case. As a negative control, all reagents were added to the last wells of the plates except cDNA and the wells were sealed with optical adhesive (Invitrogen). Subsequently, the plate was placed in a 7500 Real-Time PCR system (Applied Biosystems, Barcelona, Spain) and the following cycling parameters were used: $50^{\circ} \mathrm{C}$ for $2 \mathrm{~min}$, followed by initial denaturation at $95^{\circ} \mathrm{C}$ for $10 \mathrm{~min}$ and 40 cycles of $95^{\circ} \mathrm{C}$ for $15 \mathrm{sec}$ and $60^{\circ} \mathrm{C}$ for $60 \mathrm{sec}$. After the end of the last cycle, dissociation curve analysis was performed and no bimodal curve or amplification of abnormal signals was observed. Nonconforming samples were discarded. The $2^{-\Delta \Delta C T}$ method was used to measure the relative changes in gene expression from the qPCR experiment (Livak et al. 2001).

\section{Immunocytochemical and immunohistochemical analysis}

The slides, previously fixed by alcohol spray, were processed initially by $0.5 \%$ Triton $\mathrm{X}$ incubation. Epitope retrieval was performed by incubating the slides in Target Retrieval Solution, $\mathrm{pH} 9$ (Dako, Glostrup, Denmark) in a water bath for $40 \mathrm{~min}$ at $95^{\circ} \mathrm{C}$ under $2 \mathrm{~atm}$ in a Pascal electric pressure cooker (Biocare Medical, Concord, CA) to achieve better staining and clearer background. Endogenous peroxidase was blocked by incubating the slides with peroxidase-blocking reagent (Dako) for $5 \mathrm{~min}$. The specimens then were incubated with the primary antibody, V-ATPase C1 (clone H-300; Santa Cruz Biotechnology, Santa Cruz, CA) diluted 1:50, for $60 \mathrm{~min}$ at room temperature. The reaction was developed using the EnVision/DAB system (Dako) and the specimens were counterstained with hematoxylin.

The immunostained specimens were examined using a light microscope at $400 \mathrm{x}$. The presence of brown staining in cells was the criterion for positive staining. Smears and sections were analyzed completely over the entire slides for each case. Immunostaining intensity was classified as: 1 , negative; 2 , weakly positive; 3 , moderately positive; 4 ) strongly positive.

Thyroid cancer smears and $3 \mu \mathrm{m}$ sections were used as positive controls (Berglund et al. 2008). Sections processed as described above without the primary antibody served as negative controls.

\section{Statistical analysis}

Statistical analysis of data was performed using GraphPad Prism software 5.03. The associations between expression levels of genes and clinical information were determined using the Pearson 
correlation coefficients. The significant difference between two groups was determined using Student's $\mathrm{t}$ test; values for $p \leq 0.05$ were considered statistically significant.

\section{Results}

The mean age of the subjects was $58 \pm 12.65$ years (range: 45-80) in the OSCC group, 56.2 \pm 12.82 years (range: 42-79) in the normal contralateral mucosa group, $56.5 \pm 12.81$ years (range: $44-81$ ) in the smoker group, $56.5 \pm 13.06$ years (range: $44-81$ ) in the former smoker group, and $57 \pm 13.42$ years (range: 45-81) in the nonsmoker group. All patients in the OSCC group were alcohol drinkers and in the other groups, consumption was less than $20 \mathrm{~g}$ of alcohol/week. The site affected most commonly by OSCC was the floor of the mouth (50\%). Differences between gene expression and clinical findings, age and tumor site in the OSCC group were not statistically significant.

The expression of ATP6V1C1 in exfoliated oral mucosa cells was measured by qPCR and normalized results are given in Fig. 1. We found significantly greater gene expression in the OSCC group than in the nonsmoker groups $(p=0.0026)$, No difference was observed in gene expression between normal contralateral mucosa and nonsmoker groups, smoker and nonsmoker groups, or former smokers and nonsmoker groups.

Figure 2 illustrates the results of immunohistochemical staining using the anti-ATP6V1C1

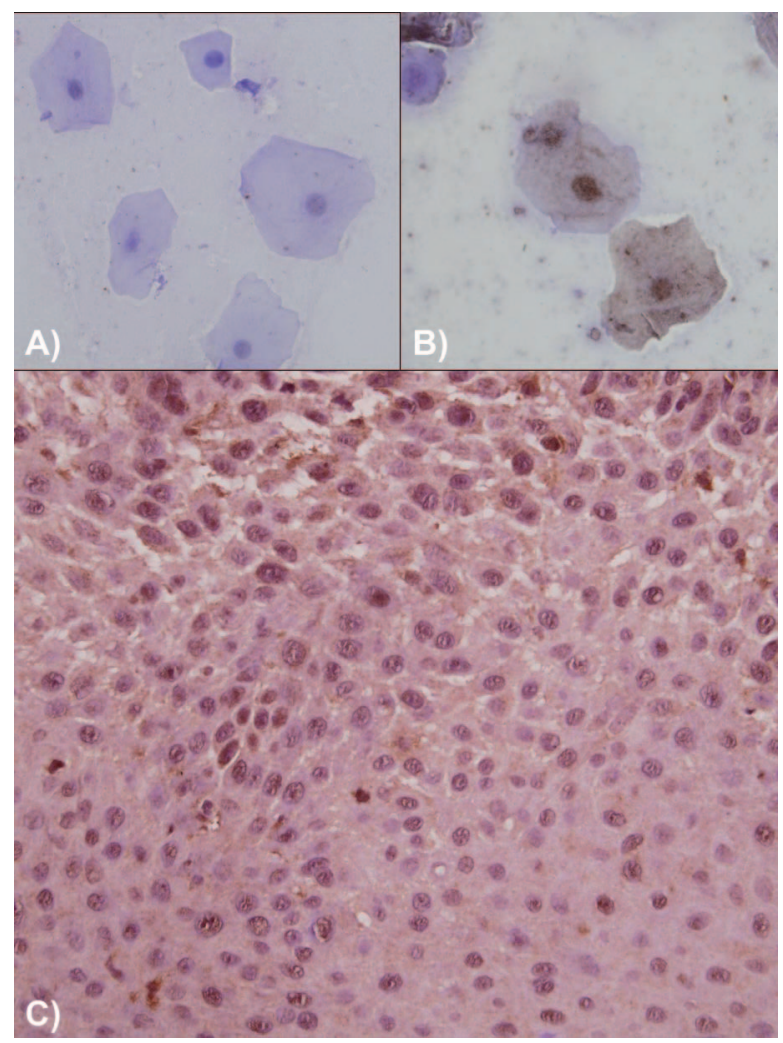

Fig. 2. Immunocytochemical and immunohistochemical staining patterns. A) Negative cytologic sample pattern in nonsmoker group. $400 \times$. B) Positive cytologic sample pattern, in smoker group. $400 \times$. C) Positive staining in OSCC samples. $400 \times$.

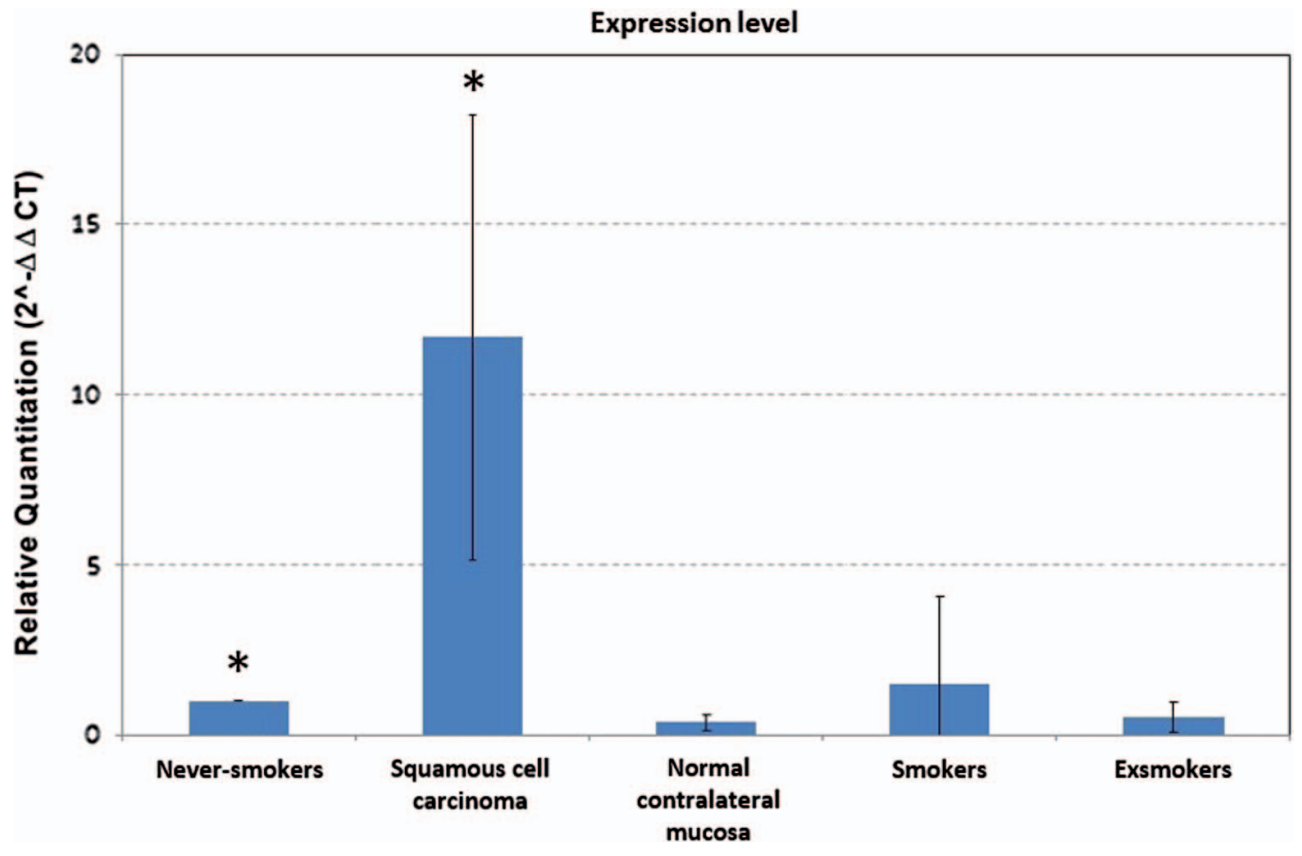

Fig. 1. Normalized results of relative expression levels of ATP6V1C1. *Difference statistically significant. 
Table 1. Primers information

\begin{tabular}{|c|c|c|}
\hline \multicolumn{2}{|c|}{ Sequences of primers } & \multirow{2}{*}{$\begin{array}{l}\text { Accession no. } \\
\text { NM_001695.4 }\end{array}$} \\
\hline ATPC6V1 & $\begin{array}{l}\text { Sense 5'-GCCATGGAAGCCATGAAC-3' } \\
\text { Antisense 5'-TGCCAGGGAAGGAATGTC-3' }\end{array}$ & \\
\hline GAPDH & $\begin{array}{l}\text { Sense 5'-AGGTCATCCATGACAACTTTG- } 3^{\prime} \\
\text { Antisense 5'-TTCAGCTCAGGGATGACCTT-3' }\end{array}$ & NM_001289746.1 \\
\hline
\end{tabular}

antibody. All OSCC cases were strongly positive. Staining was predominantly cytoplasmic, although perinuclear and nuclear expression was observed in many samples. Staining was observed rarely in the smoker group; no staining was observed in the former smoker and nonsmoker groups.

\section{Discussion}

RNA obtained from cytology samples can be used to evaluate gene expression in oral mucosal cells (Reboiras-López et al. 2012). Therefore, patients at risk of potentially malignant disorders, such as chronic smokers, could be monitored using this technique (Pérez-Sayáns et al. 2009b, 2010b).

The ATP6V1C1 gene was expressed strongly in OSCC, which suggests that the protein encoded by this gene is involved in malignant transformation (Otero-Rey et al. 2008, Pérez-Sayáns et al. 2010a); qPCR and immunohistochemistry revealed overexpression of ATP6V1C1 in exfoliated OSCC cells compared to nonsmokers.

The ATP6V1C1 gene encodes the $\mathrm{C}$ subunit of V-ATPase. The $\mathrm{C}$ subunit controls the protein complex assembly, thereby regulating V-ATPases (Inoue et al. 2005). The $C$ subunit participates in enzymatic dissociation and reversible silencing activity of V-ATPase (Zhang et al. 2006). V-ATPases participate in cell transformation, carcinogenesis and metastasis (Pérez-Sayáns et al. 2009a). V-ATPases have diverse functions in eukaryotic organisms including acidification of intracellular compartments and exportation of protons across the plasma membrane to the extracellular environment. This affects the $\mathrm{pH}$ of the tumor microenvironment (PérezSayáns et al. 2010a).

ATP6V1C1 participates in the control of V-ATPases even during early stages of carcinogenesis (Otero-Rey et al. 2008). We found no increased expression of the gene or its corresponding protein in either normal contralateral mucosa of patients with OSCC or mucosa of chronic or former smokers, however. Although our sample was small, the qPCR technique is sufficiently sensitive to detect small amounts of initial copies of genetic material; therefore, it is effective for quantifying expression levels of a gene. ATP6V1C1 is a useful marker for OSCC, but we were unable to contribute to understanding of field cancerization and the damage to the mucosa due to chronic tobacco use, because we found no changes in the expression of the gene and protein in our investigation. ATP6V1C1 protein expression was strong in all cases of OSCC. Staining was predominantly cytoplasmic, although perinuclear and nuclear expression also was observed in many samples; this observation is consistent with an earlier report (García-García et al. 2012).

In the smokers group, ATP6V1C1 protein expression was rarely positive and it was negative in the former smoker and nonsmoker groups. Few basal and parabasal cells are included in oral cytobrush smears; consequently, our findings differ from those reported earlier (García-García et al. 2012). These investigators reported the protein expression of ATP6V1C1 in normal oral mucosa tissue samples and observed expression only in the basal and intermediate layers of the epithelium; no staining was detected in the keratinized superficial layer.

We hypothesized that changes in ATP6V1C1 gene and protein expression could be observed during early stages of carcinogenesis and during field cancerization. Therefore, we analyzed the mucosae of chronic smokers, former smokers and the normal contralateral mucosa of patients with OSCC. Although all mucosae without visible alterations showed unaltered ATP6V1C1 gene and protein expression, altered ATP6V1C1 gene and protein expression was detected in the OSCC group. Therefore, it appears that ATP6V1C1 expression changes occur during later stages of carcinogenesis. Despite its limitations, our preliminary study provides a basis for future studies of using ATP6V1C1 levels to detect early stages of OSCC.

\section{Acknowledgments}

The authors thank the Coordenação de Aperfeiçoamento de Pessoal de NívelSuperior (CAPES), Fundação de Amparo à Pesquisa do Estado de São Paulo (FAPESP, Process 2012/05371-4 and 2013/06251-5) 
for financial support, Rovers Medical Devices for donating a Rovers ${ }^{\circledR}$ Orcellex $^{\circledR}$ Brush, and the Pathology Department of the University Hospital and School of Medicine of Santiago de Compostela, Spain, for their collaboration.

Declaration of interest: The authors report no conflicts of interest. The authors alone are responsible for the content and writing of this paper.

\section{References}

Baric JM, Alman JE, Feldman RS, Chauncey HH (1982) Influence of cigarette, pipe, and cigar smoking, removable partial dentures, and age on oral leukoplakia. Oral Surg. Oral Med. Oral Pathol. 54: 424-429.

Braakhuis BJ, Brakenhoff RH, Leemans CR (2005) Second field tumors: a new opportunity for cancer prevention? Oncologist 10: 493-500.

Berglund L, Björling E, Oksvold P, Fagerberg L, Asplund A, Szigyarto CA, Persson A, Ottosson J, Wernérus H, Nilsson P, Lundberg E, Sivertsson A, Navani S, Wester K, Kampf C, Hober S, Pontén F, Uhlén M (2008) A gene-centric human protein atlas for expression profiles based on antibodies. Mol. Cell Proteom. 7: 2019-2027.

Beyenbach KW, Wieczorek H (2006) The V-type H+ ATPase: molecular structure and function, physiological roles and regulation. J. Exp. Biol. 209: 577-589.

Cardone RA, Casavola V, Reshkin SJ (2005) The role of disturbed $\mathrm{pH}$ dynamics and the $\mathrm{Na}+/ \mathrm{H}+$ exchanger in metastasis. Nat. Rev. Cancer 5: 786-795.

Fontes PC, Correa GHM, Issa PC, Brandão $\mathbf{A A H}$, Almeida JD (2008) Comparison of exfoliative Pap stain and AgNOR counts of the tongue in smokers and nonsmokers. Head Neck Pathol. 2: 157-162.

García-García A, Pérez-Sayáns García M, Rodríguez MJ, Antúnez-López J, Barros-Angueira F, Somoza-Martín M, Gándara-Rey JM, Aguirre-Urízar JM (2012) Immunohistochemical localization of C1 subunit of V-ATPase (ATPase C1) in oral squamous cell cancer and normal oral mucosa. Biotech. E Histochem. 87: 133-139.

Gottlieb RA, Giesing HA, Zhu JY, Engler RL, Babior BM (1995) Cell acidification in apoptosis: granulocyte colonystimulating factor delays programmed cell death in neutrophils by up-regulating the vacuolar $\mathrm{H}(+)$-ATPase. Proc. Natl. Acad. Sci. USA 92: 5965-5968.

Inoue T, Forgac M (2005) Cysteine-mediated cross-linking indicates that subunit $\mathrm{C}$ of the V-ATPase is in close proximity to subunits $\mathrm{E}$ and $\mathrm{G}$ of the $\mathrm{V} 1$ domain and subunit a of the V0 domain. J. Biol. Chem. 280: 27896-27903.

Kaufmann R (2010) The concept of field cancerization. Melanoma Res. 20: e13-e14.

Lambert R, Sauvaget C, de Camargo Cancela M, Sankaranarayanan R (2011) Epidemiology of cancer from the oral cavity and oropharynx. Eur. J. Gastroenterol. Hepatol. 23: 633-641.

Lima CF, Oliveira LU, Cabral LA, Brandão AA, Salgado MA, Almeida JD (2010) Cytogenetic damage of oral mucosa by consumption of alcohol, tobacco and illicit drugs. J. Oral Pathol. Med. 39: 441-446.

Martinez-Zaguilan R, Lynch RM, Martinez GM, Gillies RJ (1993) Vacuolar-H(+)-ATPases are functionally expressed in plasma membranes of human tumor cells. Am. J. Physiol. 265: C1015-C1029.

Otero-Rey EM, Somoza-Martín M, Barros-Angueira F, García-García A (2008) Intracellular $\mathrm{pH}$ regulation in oral squamous cell carcinoma is mediated by increased V-ATPase activity via over-expression of the ATP6V1C1 gene. Oral Oncol. 44: 193-199.

Pavanello MB, Prado FA, Balducci I, Brandão AA, Almeida JD (2006) Cytologic analysis of alterations induced by smoking and by alcohol consumption. Acta Cytol. 50: 435-440.

Pérez-Sayáns M, García-García A, Reboiras-López MD, Gándara-Vila P (2009a) Role of V-ATPases in solid tumors: importance of the subunit C (Review). Int. J. Oncol. 34: 1513-1520.

Pérez-Sayáns M, Somoza-Martín JM, Barros-Angueira F, Reboiras-López MD, Gándara Rey JM, García-García A (2009b) Genetic and molecular alterations associated with oral squamous cell cancer (Review). Oncol. Rep. 22: 1277-1282.

Pérez-Sayáns M, Reboiras-López MD, Somoza-Martín JM, Barros-Angueira F, Diz PG, Rey JM, García-García A (2010a) Measurement of ATP6V1C1 expression in brush cytology samples as a diagnostic and prognostic marker in oral squamous cell carcinoma. Cancer Biol. Ther. 9: 1057-1064.

Pérez-Sayáns M, Somoza-Martín JM, Barros-Angueira F, Reboiras-López MD, Gándara-Vila P, Gándara Rey JM, García-García A (2010b) Exfoliative cytology for diagnosing oral cancer. Biotech. E Histochem. 85: 177-187.

Reboiras-López MD1, Pérez-Sayáns M, Somoza-Martín JM, Gayoso-Diz P, Barros-Angueira F, Gándara-Rey JM, García-García A (2012) Comparison of the Cytobrush ${ }^{\circledR}$, dermatological curette and oral CDx ${ }^{\circledR}$ brush test as methods for obtaining samples of RNA for molecular analysis of oral cytology. Cytopathology 23: 192-197.

Reshkin SJ, Bellizzi A, Albarani V, Guerra L, Tommasino M, Paradiso A, Casavola V (2000) Phosphoinositide 3-kinase is involved in the tumor-specific activation of human breast cancer cell $\mathrm{Na}(+) / \mathrm{H}(+)$ exchange, motility, and invasion induced by serum deprivation. J. Biol. Chem. 275: 5361-5369.

Scully C, Field JK, Tanzawa H (2000) Genetic aberrations in oral or head and neck squamous cell carcinoma 2: chromosomal aberrations. Oral Oncol. 36: 311-327.

Winn DM (2001) Tobacco use and oral diseases. J. Dent. Ed. 65: 306-312.

Zhang Z, Inoue T, Forgac M, Wilkens S (2006) Localization of subunit C (Vma5p) in the yeast vacuolar ATPase by immunoelectron microscopy. FEBS Lett. 580: 2006-20010. 